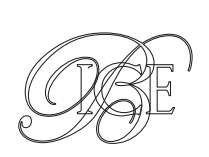

\title{
CUATRO AÑOS DEL CETA: CÓMO HA SIDO APROVECHADO POR LAS EMPRESAS ESPAÑOLAS
}

Al cumplirse el cuarto año desde la entrada en vigor provisional del acuerdo CETA de liberalización del comercio y las inversiones entre la UE y Canadá, hacemos un repaso de las principales disposiciones del acuerdo y el interés que tienen para las empresas españolas. Analizamos la evolución del comercio antes y después del desarme arancelario del CETA y el aprovechamiento que están haciendo del acuerdo las empresas exportadoras españolas.

Palabras clave: Canadá, acuerdo, comercio, flujos.

Clasificación JEL: F13, F14.

\section{Introducción}

Hace cuatro años, el 17 de septiembre de 2017, entró en vigor provisionalmente ${ }^{1}$ el Acuerdo Económico y Comercial Global, CETA², entre la UE y Canadá, que rige en la actualidad como marco para las relaciones comerciales entre España y Canadá. El CETA es un «acuerdo comercial progresivo» ${ }^{3}$ de nueva generación y es

\footnotetext{
* Analista de Mercado. Oficina Económica y Comercial de España en Ottawa.

Versión de agosto de 2021.

DOI: https://doi.org/10.32796/bice.2021.3140.7280

1 Se trata de un acuerdo de competencia mixta, por lo que únicamente las partes que son competencia exclusiva de la Comisión Europea estarán en vigor mientras todos los Estados miembros de la UE no lo hayan ratificado. Quedan doce EE. MM. de la UE que no han completado sus procesos de ratificación: https://www.consilium.europa.eu/en/documentspublications/treaties-agreements/agreement/?id=2016017. La mayor parte del acuerdo ya se aplica. Los ámbitos que aún no están en vigor son la protección de las inversiones y el Sistema de Tribunales de Inversiones (ICS), así como ciertas disposiciones sobre inversiones y sobre la transparencia de los procedimientos administrativos, la revisión y el recurso a nivel de los Estados miembros.

2 Comprehensive Economic and Trade Agreement. Usaremos el acrónimo en inglés del acuerdo para referirnos a este, puesto que es de uso más común.

3 https://ec.europa.eu/trade/policy/in-focus/ceta/ceta-explained/
}

uno de los tratados de libre comercio (TLC) más ambiciosos que se hayan negociado entre dos economías avanzadas de nivel comparable. Partiendo de un nivel de barreras arancelarias bajo, busca, además del tradicional desarme arancelario de un TLC, eliminar o reducir barreras no arancelarias y liberalizar el comercio de servicios, el movimiento de personas y las inversiones. Incluye también aspectos novedosos en un TLC como son una cobertura ambiciosa para el acceso a mercado de las compras públicas o compromisos regulatorios para la protección de inversiones, los derechos laborales y el medioambiente, todo ello desde la perspectiva de crear oportunidades tanto para las grandes como las pequeñas empresas.

La entrada en vigor provisional del CETA supuso un hito importante en nuestras relaciones comerciales con Canadá, ya que abría nuevas e interesantes oportunidades para las empresas españolas. Podemos empezar a analizar ahora con la perspectiva que nos $D$ 
dan estos cuatro años de recorrido para ver si se han materializado y en qué medida.

No se pretende hacer un análisis exhaustivo del contenido del CETA, puesto que existen numerosos artículos ${ }^{4}$ y trabajos que lo ilustran, sin contar con los recursos que la propia Comisión Europea o la Secretaría de Estado de Comercio ponen a disposición del público y las empresas en sus portales ${ }^{5,6}$, sino que veremos las disposiciones que creemos son las más relevantes para las empresas españolas.

Nos centraremos, por lo tanto, en una primera parte del artículo en aspectos concretos del CETA que ilustran la importancia práctica de este acuerdo para las empresas españolas, haciendo alguna referencia a la actual presencia española en Canadá.

En una segunda parte haremos un análisis de la evolución de los flujos comerciales entre España y Canadá desde la entrada en vigor del CETA y resaltaremos el grado de aprovechamiento que las empresas han hecho de las preferencias arancelarias que ofrece. Por falta de espacio, nos ceñiremos al comercio de bienes y no intentaremos abarcar otros aspectos de la relación comercial entre España y Canadá como el comercio de servicios o las inversiones.

\section{Contenido del CETA}

La entrada en vigor del CETA supuso la eliminación inmediata, desde la misma fecha de entrada en vigor provisional del acuerdo, de la totalidad de aranceles sobre el $98 \%$ de las

\footnotetext{
Véase, por ejemplo, Serrano (2021) en bibliografía.

5 https://ec.europa.eu/trade/policy/in-focus/ceta/ceta-chapter-bychapter/

6 https://comercio.gob.es/PoliticaComercialUE/AcuerdosComerciales/ Documents/171101-FICHAS_CETA.PDF
}

líneas arancelarias ${ }^{7}$ del comercio entre la UE y Canadá. A esto se añade un $1 \%$ adicional de líneas que irán desapareciendo paulatinamente sobre periodos de tres a siete años ${ }^{8}$, y que corresponden a productos considerados como sensibles ${ }^{9}$.

Por grandes sectores, finalizados los plazos de transición, quedarán exentos de aranceles el $92 \%$ de las exportaciones de productos agrícolas y alimentarios a Canadá y la totalidad de los productos industriales. El $8 \%$ restante de líneas arancelarias de productos agrícolas y alimentarios corresponden a productos sensibles que no se van a liberalizar. Estos productos quedarán sometidos a contingentes arancelarios libres de derechos (como el queso, en el caso de Canadá; o la carne de vacuno, de porcino y el maíz dulce, en el caso de la UE) o bien quedarán completamente excluidos de los compromisos de desarme arancelario.

La eliminación de aranceles supone un ahoro considerable en derechos de aduana para los productos de la UE. La Comisión Europea lo estimó en 590 millones de euros anuales cuando hayan finalizado todos los periodos transitorios ${ }^{10}$, lo que en última instancia se traduce en mayor competitividad de nuestras exportaciones.

En productos lácteos, Canadá ha abierto dos nuevos contingentes arancelarios para quesos de la UE. El primero para queso de venta al público, de 16.000 toneladas anuales, y el segundo, de 1.700 toneladas anuales, para queso de uso industrial. Estos nuevos contingentes se irán alcanzando por incrementos $\triangleright$

\footnotetext{
7 Eliminación de aranceles sobre el 98,2\% de las líneas arancelarias de Canadá y $97,7 \%$ de la UE.

8 Texto CETA, Anexo 2A, eliminación arancelaria: https://data. consilium.europa.eu/doc/document/ST-10973-2016-ADD-1/es/pdf

9 Texto CETA, Anexo 2A, lista arancelaria de Canadá: https://data. consilium.europa.eu/doc/document/ST-10973-2016-ADD-2/es/pdf\# page $=2$

$10 \mathrm{http}: / /$ trade.ec.europa.eu/doclib/press/index.cfm?id=1525
} 
anuales sobre un periodo de transición de seis años. Para 2021, la cuota de queso para consumo es de 13.333 toneladas métricas y la cuota de queso industrial, de 1.417 toneladas métricas.

Además, Canadá ha «reasignado» a la UE una parte adicional de la cuota de importación de quesos de países OMC (Organización Mundial del Comercio), a la que ya correspondía en exclusiva el $66 \%$ (20.400 toneladas anuales), y ahora le corresponderá el $70 \%$. En total, entre el CETA y la cuota OMC, serán hasta 31.970 toneladas métricas de queso que podrá entrar en Canadá libre de aranceles cada año.

Para otros productos agroalimentarios, desaparecen los aranceles sobre algunas de nuestras exportaciones más emblemáticas, como la aceituna ( $8 \%$ ) y el turrón de Alicante (10\%).

Quedan protegidas por el acuerdo 24 denominaciones de origen de productos agroalimentarios españoles ${ }^{11}$, que incluyen aceites de oliva, productos cárnicos, queso, turrones, cítricos y especias. Por nombre, además del turrón de Alicante mencionado anteriormente, quedan protegidos productos como el azafrán de La Mancha, el jamón de Guijuelo, el queso manchego o los cítricos valencianos, así como productos menos conocidos en Canadá, como el aceite de Baena o el salchichón de Vic. La protección de nuestras denominaciones de vinos, que ya contaban con la protección de los acuerdos específicos ${ }^{12}$ de 2003 y 1989, queda ahora también sujeta a la disciplina del acuerdo y, llegado el caso, a su régimen de solución de diferencias.

Los productores de estas denominaciones podrán apostar por este mercado, aportando

\footnotetext{
11 Texto CETA, Anexo 20A, https://data.consilium.europa.eu/doc/ document/ST-10973-2016-ADD-5/es/pdf\#page=2

12 Acuerdo sobre bebidas alcohólicas (1989) y Acuerdo sobre el Comercio de Vinos y Licores (2003).
}

una mayor variedad de productos de alta calidad al consumidor canadiense, con la seguridad de que sus denominaciones de origen gozan de protección frente a competidores desleales.

En vinos, el arancel de importación era bajo y ha quedado también abolido. EI CETA aporta, quizá de forma más importante que la eliminación arancelaria, una garantía sólida de trato equitativo para nuestras bodegas y una respuesta más eficaz a las múltiples discriminaciones que aplican los monopolios provinciales de bebidas alcohólicas a los productos importados. El más significativo, el denominado «diferencial de coste de servicio» ${ }^{13}$ entre productos nacionales e importados, no podrá calcularse de ahora en adelante en porcentaje del valor de la importación, sino que tendrá que ser calculado en volumen y reflejar costes reales de distribución y promoción. Y dichos costes deberán ser auditados y comunicados de forma transparente en las propias páginas de internet de los monopolios.

Para productos no agrícolas, el arancel medio de Canadá partía también de un nivel bastante bajo, por lo que hay que fijarse en aquellos productos concretos para los cuales existían picos arancelarios importantes antes de la entrada en vigor del acuerdo. Por ejemplo, en maquinaria y productos eléctricos, algunos picos alcanzaban el $9 \%$ del valor en aduana; en combustibles como el gas natural, el $12,5 \%$; o en moda, calzado y azulejo cerámico, un $18 \%$. Ganamos también en que no habrá necesidad de duplicar certificaciones técnicas para productos industriales a ambos lados del Atlántico, puesto que los fabricantes españoles podrán certificar sus productos de acuerdo $\triangleright$

13 Algunos monopolios aplican un diferencial de precio entre productos nacionales y de importación justificado por la diferencia de costos relacionados con el marketing, la manipulación y la distribución. 
con la norma canadiense en laboratorios de la UE, con pleno reconocimiento en Canadá.

Otro de los grandes logros del nuevo acuerdo entre la UE y Canadá, el que más interés ha levantado sin duda en muchas de nuestras empresas, es la apertura del mercado de las compras públicas en todos los niveles de Administración: federal, provincial y municipal, incluyendo empresas públicas. Es este un hito sin precedentes, la mayor concesión hecha por Canadá a un socio comercial hasta la fecha y que da una gran ventaja a las empresas de la UE sobre proveedores de otros países ${ }^{14}$. Canadá y la UE se han comprometido también a que los procesos de licitación sean más transparentes. Canadá, en particular, tendrá que crear un portal electrónico para dar publicidad a todos los anuncios de licitaciones cubiertas por el CETA, con fecha límite del 21 de septiembre de 2022, lo que sin duda ayudará a las empresas españolas a identificar las oportunidades que puedan existir sin incurrir en desproporcionados costes de búsqueda.

Nuestras principales empresas constructoras y de ingeniería llevan ya varios años trabajando con mucho éxito en el mercado canadiense. Han desarrollado hasta la fecha proyectos importantes y de gran envergadura, que requieren, además de una fuerte capacidad técnica, la capacidad de estructurar proyectos en régimen de partenariado público privado.

Por lo tanto, no cabe duda de que la entrada en vigor del capítulo de compras públicas del CETA, en conjunción con los ambiciosos planes de inversión en infraestructuras tanto del Gobierno federal como de los Gobiernos provinciales, representa una gran oportunidad

14 https://trade.ec.europa.eu/doclib/docs/2020/february/tradoc_ 158655.pdf para nuestras empresas de diversos tipos de infraestructura. $Y$ no solo para ellas, conviene recalcarlo, sino también para empresas de ingeniería o de fabricación de estructuras especializadas que colaboran habitualmente con ellas.

Pasando a otros ámbitos del acuerdo, en el comercio de servicios y las inversiones también cabe esperar para las empresas españolas una mejora notable en el acceso al mercado de los servicios de Canadá, que hasta ahora se restringía a las concesiones del Acuerdo de Comercio de Servicios de la OMC, y en las que se mantenían reservas de acceso al mercado para muchos sectores y actividades. Existían, por ejemplo, restricciones a la práctica en territorio canadiense para profesionales como abogados, contables, arquitectos o ingenieros y limitaciones a la inversión extranjera en sectores importantes, como en servicios postales y mensajería, servicios financieros y telecomunicaciones.

Con la entrada en vigor del CETA, las relaciones comerciales en el ámbito de los servicios entran en una nueva etapa, donde se entiende que todos los sectores están abiertos a las empresas de ambas partes contratantes, excepto en aquellos casos en los que se haya definido específicamente en el acuerdo ${ }^{15}$.

Abrir nuevos mercados para los servicios españoles es un aspecto importante del CETA, puesto que fomentará la movilidad profesional y las inversiones entre ambas partes.

La movilidad se verá además reforzada por las disposiciones del acuerdo para facilitar la transferencia de personal entre filiales de $D$

\footnotetext{
15 CETA es el primer acuerdo de la UE que usa «listas negativas» de reservas para definir los sectores de servicios cuyo comercio no se liberaliza. Bajo este concepto, todo queda liberalizado de entrada salvo lo que quede recogido en las reservas del acuerdo. Es un concepto mucho más abierto y ambicioso que el de «listas positivas» utilizado anteriormente para definir únicamente aquellos sectores abiertos y comprometidos. A diferencia de la UE, Canadá sí tenía experiencia en el uso de listas negativas por el acuerdo NAFTA (North American Free Trade Agreement).
} 
Canadá y la UE, el envío de personal para dar servicio posventa o postleasing de maquinaria, software y otros equipos, así como facilitar el reconocimiento de cualificaciones entre profesiones regladas, como arquitectos o ingenieros. En este sentido, la UE y Canadá están negociando, con vistas a finalizar el proceso próximamente, el primer Acuerdo de Reconocimiento Mutuo de cualificaciones en el marco del CETA para la profesión de arquitecto, y que servirá de modelo para futuros acuerdos.

Las inversiones de empresas españolas en Canadá quedarán, asimismo, sujetas al nuevo umbral establecido para la revisión de inversiones ${ }^{16}$ que se originan en la UE. Este umbral será de 1.565 millones de dólares (1.056 millones de euros) en 2021. Además, España, que no contaba con un tratado bilateral de protección de inversiones con Canadá, gozará de la protección del CETA en la materia cuando entren en vigor las provisiones relativas al nuevo Sistema de Tribunales de Inversiones (ICS).

$\mathrm{Y}$ finalmente, en el ámbito de la protección de la propiedad intelectual, el CETA introduce notables mejoras en la protección de marcas, patentes y derechos de autor. En la protección de marcas hay que incluir la protección de nuestras denominaciones de origen, que bajo legislación canadiense se consideran marcas comerciales. Como tales gozan no solo de la protección como marca registrada frente a competidores desleales en Canadá, sino que podrán reclamar también la asistencia de las autoridades aduaneras canadienses para frenar la entrada de productos que infrinjan sus derechos de propiedad provenientes de terceros países.

16 La ventaja comparativa que confiere este umbral de revisión más elevado ha quedado erosionada con la entrada en vigor del CETA, puesto que ahora es el mismo para todos los países que tienen un TLC con Canadá y solo 500 millones de dólares más elevado que el umbral para países OMC sin TLC.
Las patentes farmacéuticas también encuentran en el CETA una mejora de las condiciones de protección hasta niveles similares a los que ofrece la normativa de la UE. En especial, tanto fabricantes de medicamentos con patente como fabricantes de genéricos recibirán un trato equitativo frente a recursos administrativos y judiciales que antes no existían y favorecían a los fabricantes de genéricos.

También existirá, para los fabricantes de productos con patente, la posibilidad de extender la vida de una patente hasta dos años, para tomar en cuenta el periodo de tiempo que puede transcurrir entre el momento de obtener la patente y el momento de recibir la autorización que permite la comercialización del medicamento, y obtienen un periodo de exclusividad de ocho años de los datos clínicos de seguridad y eficacia de un medicamento patentado durante los cuales no pueden ser utilizados por terceros para desarrollar una versión genérica.

\section{Efectos del CETA sobre la balanza comercial española: evolución y aprovechamiento de preferencias arancelarias por parte de las empresas españolas}

El punto de partida de la relación comercial de la Unión Europea con Canadá antes del CETA era el de un comercio en el que un porcentaje muy elevado de bienes $(75,8 \%$ en 2016) $)^{17}$ circulaba libre de aranceles, incluso bajo el régimen de nación más favorecida (NMF) de la OMC, el que regía las $\triangleright$ 
relaciones comerciales antes de que entrara en vigor el CETA. Con la entrada en vigor del acuerdo, se logra trasladar a un régimen preferencial con aranceles nulos o significativamente reducidos una parte del comercio que era NMF con aranceles positivos.

\subsection{Grado de aprovechamiento de las preferencias arancelarias dentro del CETA}

El grado de aprovechamiento de las preferencias arancelarias (Preference Utilisation Rate o PUR $)^{18}$, la ratio entre el comercio que circula al amparo de un TLC y el que, pudiendo hacerlo, no lo hace, es un criterio de éxito y aceptación de un TLC. En el caso del CETA, el PUR de las exportaciones a Canadá a nivel UE-27 $7^{19}$ empezó en un nivel bajo: apenas un $38 \%$ de las exportaciones usaron las preferencias arancelarias que otorga el acuerdo en 2018 , comparado con un $52 \%$ de las exportaciones de Canadá a la UE-27. En 2019 y 2020, el PUR de las exportaciones de la UE ha experimentado un aumento medio de 9,5 puntos porcentuales al año, para situarse en un $56 \%$ en 2020; un nivel similar al de las exportaciones de Canadá, del $57 \% 20$.

Sin embargo, el desglose del comercio bilateral con Canadá por Estado miembro y por productos revela que el grado de aprovechamiento de las preferencias arancelarias es muy dispar. En el caso de España, los datos indican que los exportadores españoles están familiarizados con estas preferencias y que las están aprovechando mejor que muchos

\footnotetext{
18 https://trade.ec.europa.eu/doclib/docs/2020/november/ tradoc 159041.pdf

19 Con la exclusión del Reino Unido.

20 https://trade.ec.europa.eu/doclib/docs/2021/april/tradoc_159548.
}

otros Estados miembros de la UE. En los dos primeros años completos de aplicación de las preferencias arancelarias del CETA ${ }^{21}$, la parte de la exportación española sometida a un arancel NMF positivo ha disminuido y la parte correspondiente al uso de preferencias ha aumentado.

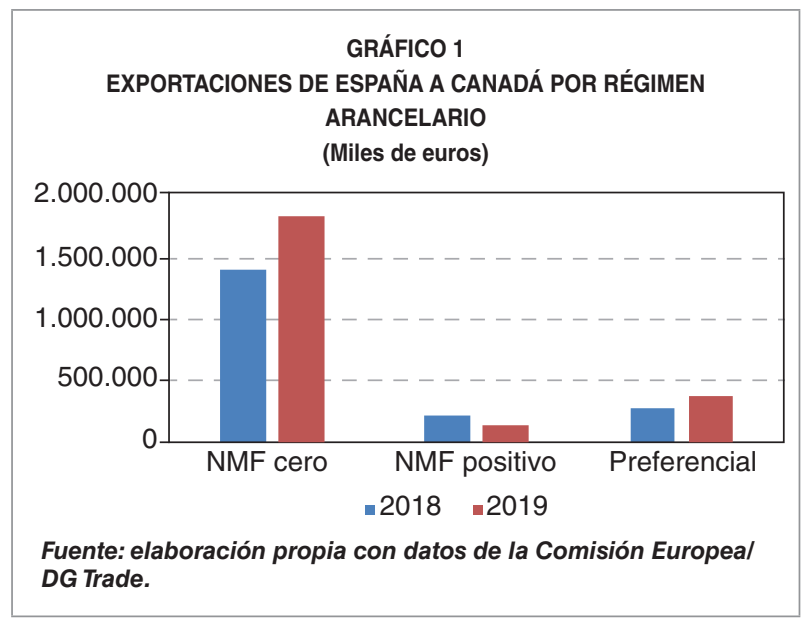

En 2019 , un $22 \%$ de las exportaciones españolas tenían derecho a acogerse a las preferencias arancelarias del CETA; un 16\% lo hizo de forma efectiva.

Incluso en el primer año completo de aplicación del CETA, 2018, el PUR de España, con un $56 \%$, se situaba ya 18 puntos porcentuales (pp) por encima de la media UE-27, que era del $38 \%$. En 2019, el PUR de España subió al $72 \%$, o 24 pp por encima de la media UE-27, del $48 \%$. Indica que los exportadores españoles han logrado aprovechar de forma mucho más efectiva que sus competidores de otros Estados miembro las preferencias arancelarias del CETA.

Dentro de la exportación española, encontramos una gran disparidad en el grado de aprovechamiento de preferencias entre las diferentes secciones del arancel.

21 Los datos desagregados a nivel de Estado miembro solo están disponibles para el periodo 2017-2019. 
CUADRO 1

EXPORTACIONES DE ESPAÑA A CANADÁ EN 2019

\begin{tabular}{|c|c|c|c|c|c|c|}
\hline Año & PUR & $\begin{array}{c}\text { Total } \\
\text { (Miles de euros) }\end{array}$ & NMF cero & NMF positivo & Preferencial efectivo & Preferencial potencial \\
\hline 2018 & $56 \%$ & 1.903 .645 & $74 \%$ & $12 \%$ & $14 \%$ & $26 \%$ \\
2019 & $72 \%$ & 2.346 .384 & $78 \%$ & $6 \%$ & $16 \%$ & $22 \%$ \\
\hline \multicolumn{2}{|l}{ Fuente: elaboración propia con datos de la Comisión Europea/DG Trade. } \\
\hline
\end{tabular}

CUADRO 2

PUR DE LA EXPORTACIÓN ESPAÑOLA A CANADÁ EN 2019

\begin{tabular}{|c|c|c|c|}
\hline Producto & $\begin{array}{l}\text { PUR España } \\
\text { (\%) }\end{array}$ & $\begin{array}{c}\text { Peso preferencias potenciales } \\
\text { en la exportación (\%) }\end{array}$ & $\begin{array}{l}\text { Intensidad } \\
\text { aprovechamiento* }\end{array}$ \\
\hline XXI. Obras de arte & 100 & 0 & - \\
\hline XIII. Manufacturas de piedra, yeso, cemento, amianto ........ & 95 & 77 & 1,2 \\
\hline 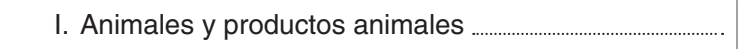 & 92 & 20 & 4,6 \\
\hline 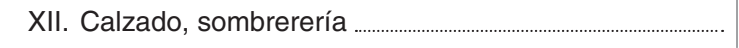 & 85 & 99 & 0,9 \\
\hline VII. Plásticos y goma & 84 & 49 & 1,7 \\
\hline XVIII. Instrumentos: de medición, musicales .... & 82 & 6 & 13,3 \\
\hline IV. Alimentos preparados & 79 & 64 & 1,2 \\
\hline III. Aceites animales o vegetales & 78 & 5 & 15,9 \\
\hline IX. Madera y productos de madera & 77 & 7 & 10,4 \\
\hline XVII. Equipo de transporte & 70 & 84 & 0,8 \\
\hline 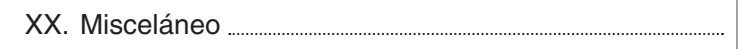 & 65 & 38 & 1,7 \\
\hline XVI. Maquinaria y aplicaciones mecánicas ……………………............. & 61 & 1 & 56,0 \\
\hline XI. Textiles y artículos textiles ………………………………………….... & 60 & 59 & 1,0 \\
\hline 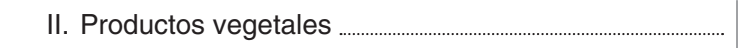 & 55 & 0 & 283,4 \\
\hline 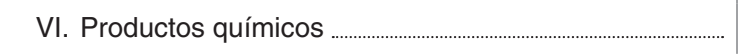 & 48 & 9 & 5,4 \\
\hline 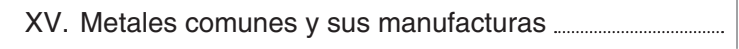 & 35 & 9 & 4,1 \\
\hline VIII. Cueros y pieles, cuero & 29 & 97 & 0,3 \\
\hline XIV. Perlas, piedras (semi) preciosas y metales ........................... & 19 & 96 & 0,2 \\
\hline 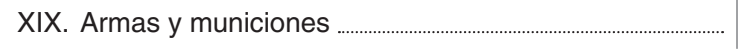 & 3 & 88 & 0,0 \\
\hline V. Productos minerales ………................................ & 0 & 0 & 3,7 \\
\hline \multicolumn{4}{|c|}{$\begin{array}{l}\text { * Ratio del PUR / peso de la exportación con derecho a preferencia CETA. Un valor mayor que } 1 \text { indica que el grado de aprovechamiento de las prefe- } \\
\text { rencias a las que tiene derecho la exportación de una sección es cualitativamente superior al peso que tiene en la exportación total española. Un valor } \\
\text { cercano a } 1 \text { indica un equilibrio entre el uso de preferencias y el peso de la sección en la exportación. Un valor menor que } 1 \text { indicaría un infra aprove- } \\
\text { chamiento de las preferencias a las que se podría acceder. }\end{array}$} \\
\hline \multicolumn{4}{|c|}{ Fuente: elaboración propia con datos de la Comisión Europea/DG Trade. } \\
\hline
\end{tabular}

\subsection{Evolución de los flujos comerciales bilaterales España-Canadá tras el CETA}

Los flujos comerciales entre España y Canadá son modestos (1.882 millones de euros de exportación en 2020; 1.331 millones de euros de importación), aunque con una tendencia ascendente desde 2014, ininterrumpida para las exportaciones hasta 2020, cuando se ve truncada por el efecto COVID. Las importaciones habían iniciado una contracción en 2019. A pesar de los cierres de actividades en España y Canadá, las exportaciones cayeron únicamente un $6,7 \%$ y las importaciones un $14,9 \%$ entre 2019 y 2020. 


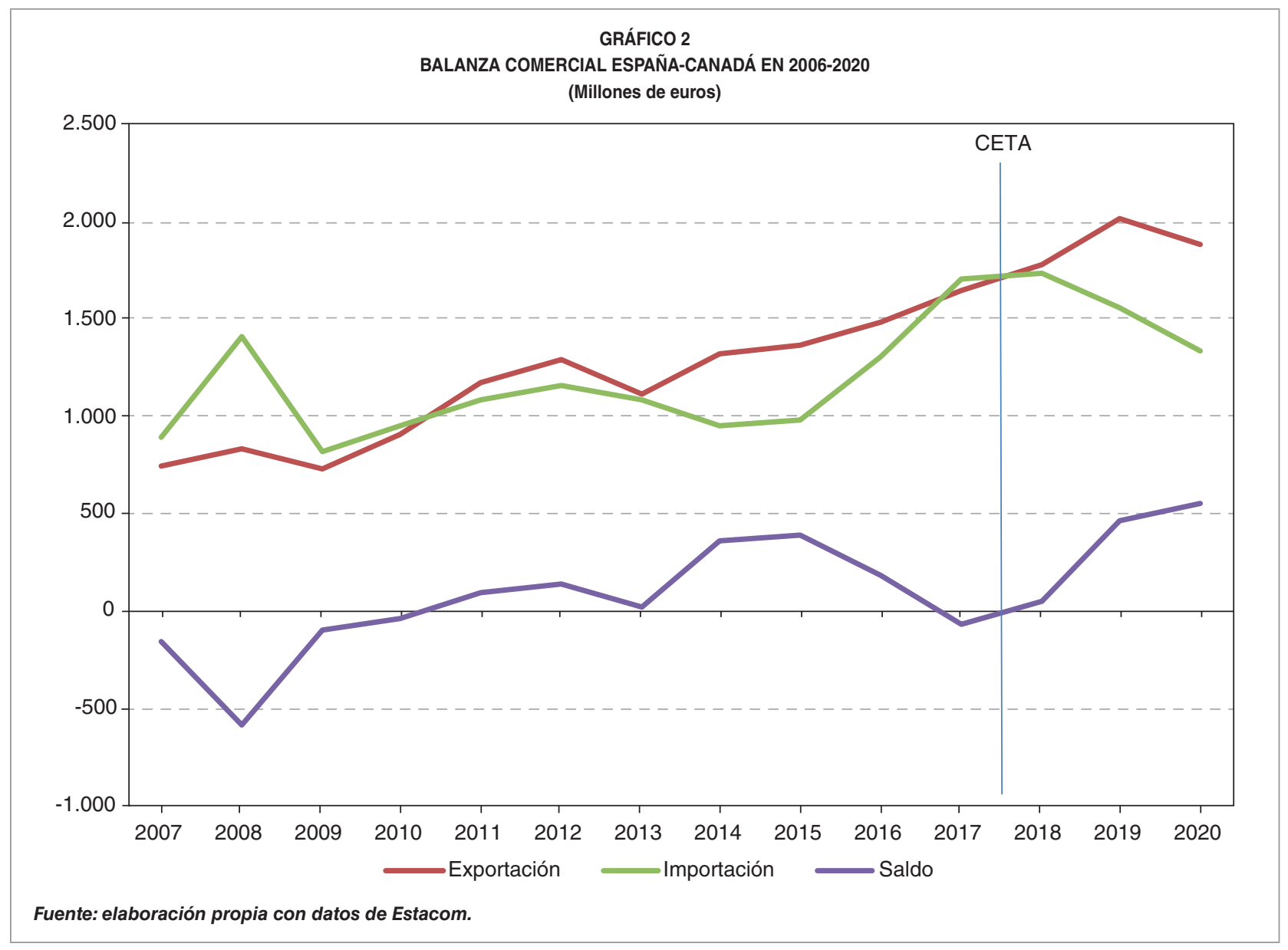

La entrada en vigor del CETA no ha tenido un impacto claro sobre el volumen de intercambios comerciales si lo examinamos como dato agregado. La tendencia de crecimiento de las exportaciones se mantiene y las importaciones se contraen. Como hemos visto anteriormente, el desarme arancelario acordado en el CETA partía de un arancel medio bajo (3,9\%) y un alto porcentaje de comercio circulaba libre de aranceles en régimen de nación más favorecida.

CUADRO 3

TASA DE CRECIMIENTO DE LAS EXPORTACIONES ESPAÑOLAS EN 2014-2020

\begin{tabular}{|c|c|c|c|c|c|c|}
\hline $\mathbf{2 0 1 4}$ & $\mathbf{2 0 1 5}$ & $\mathbf{2 0 1 6}$ & $\mathbf{2 0 1 7}$ & $\mathbf{2 0 1 8}$ & $\mathbf{2 0 1 9}$ & $\mathbf{2 0 2 0}$ \\
\hline $18,1 \%$ & $4,2 \%$ & $8,6 \%$ & $10,5 \%$ & $8,6 \%$ & $13,0 \%$ & $-6,7 \%$ \\
\hline
\end{tabular}

Fuente: elaboración propia con datos de Estacom.

El impacto de las medidas para frenar la propagación del virus de la COVID-19 queda patente en la evolución de los flujos de comercio entre España y Canadá a partir del mes de marzo de 2020, con caídas sin precedentes en casi todos los meses hasta el verano y, en el caso de las importaciones, hasta el otoño de ese año (Gráfico 3).

Las primeras medidas por la COVID-19 empezaron en marzo de 2020 y se hicieron más restrictivas en abril. El impacto en el comercio bilateral fue inmediato y profundo (Gráfico 4). Sin embargo, las importaciones sufrieron más que las exportaciones. En febrero, las exportaciones de España a Canadá cayeron un 47,3\%, comparado con el mismo periodo de 2019, y siguieron cayendo hasta agosto de 2020 , pero siempre a un ritmo inferior al de febrero. En el otoño, una segunda ola de la pandemia forzó a restringir nuevamente actividades no $D$ 

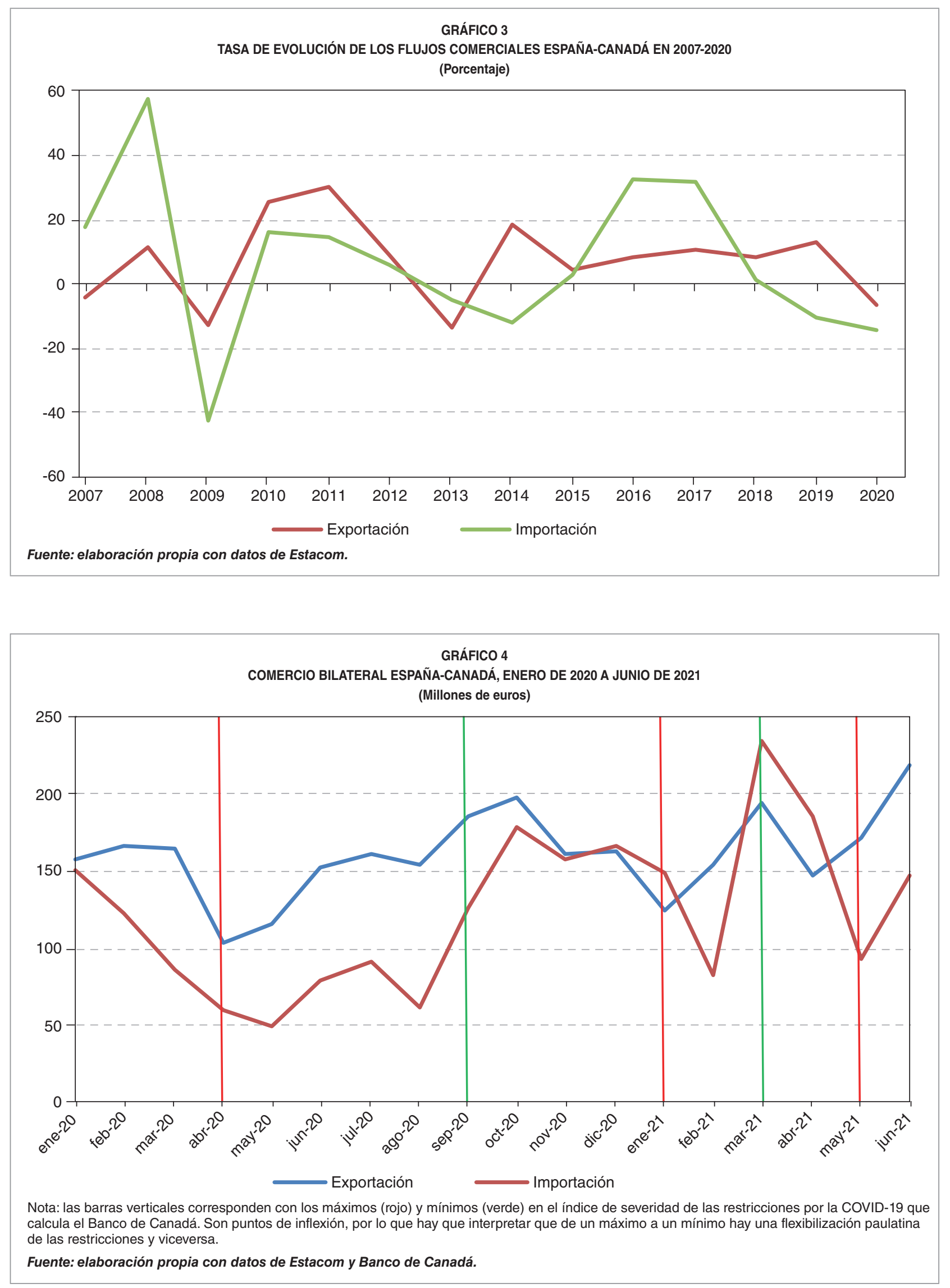


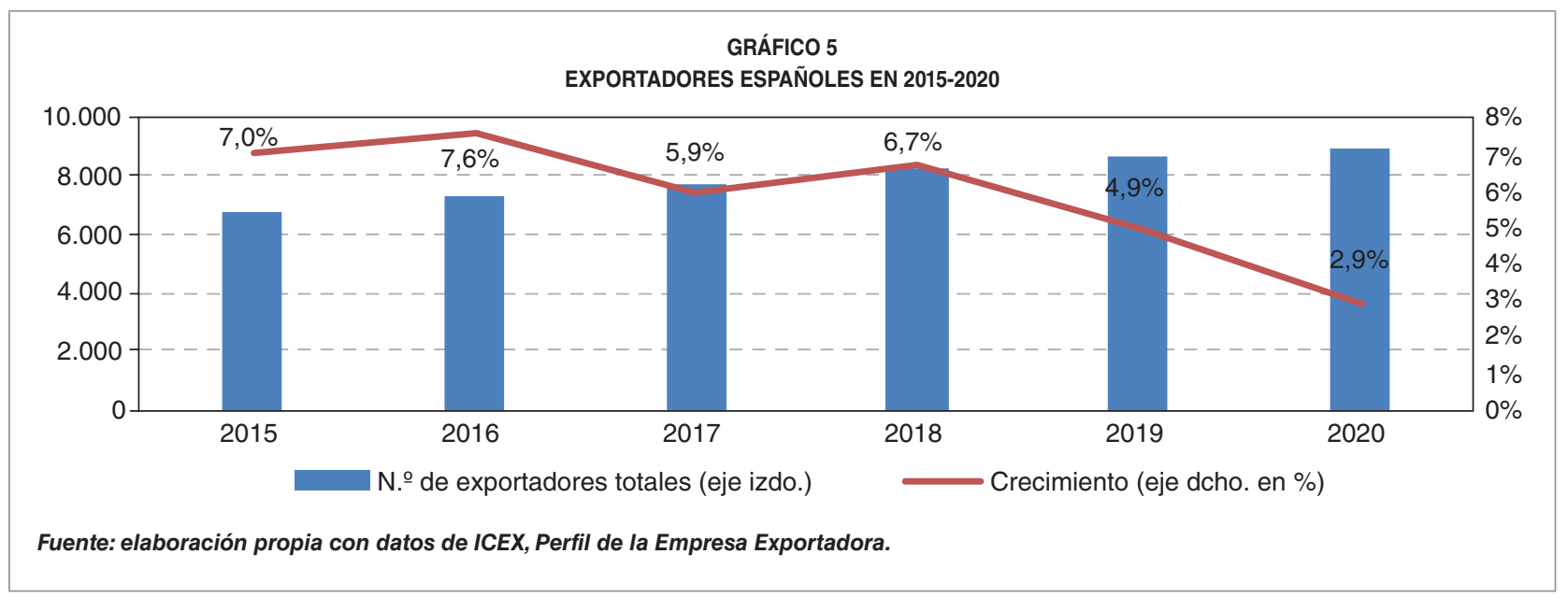

esenciales hasta la primavera de 2021 y la tercera ola surge inmediatamente después, lo que se refleja en los datos de comercio nuevamente.

Si miramos al impacto del CETA, esta vez sobre el número de empresas que exportan a Canadá, vemos que se mantiene una tendencia de crecimiento continuado del número de exportadores cada año con tendencia a moderarse desde la entrada en vigor del acuerdo.

Donde el análisis se vuelve más interesante es a la vista del dato de la actividad de las empresas que exportan a Canadá con regularidad (las empresas que han exportado en los últimos cuatro años consecutivos).

Con la entrada en vigor provisional del CETA se aprecia un ligero aumento en el número de empresas españolas que consolidan una actividad exportadora regular en el mercado canadiense, pero donde realmente se aprecia el efecto positivo es en el volumen de exportación de estas empresas. Así, aunque el número de empresas exportadoras regulares a Canadá aumenta un $6,5 \%$ en 2017 y un $7,7 \%$ en $\triangleright$

GRÁFICO 6

EXPORTADORES REGULARES ESPAÑOLES EN 2015-2020

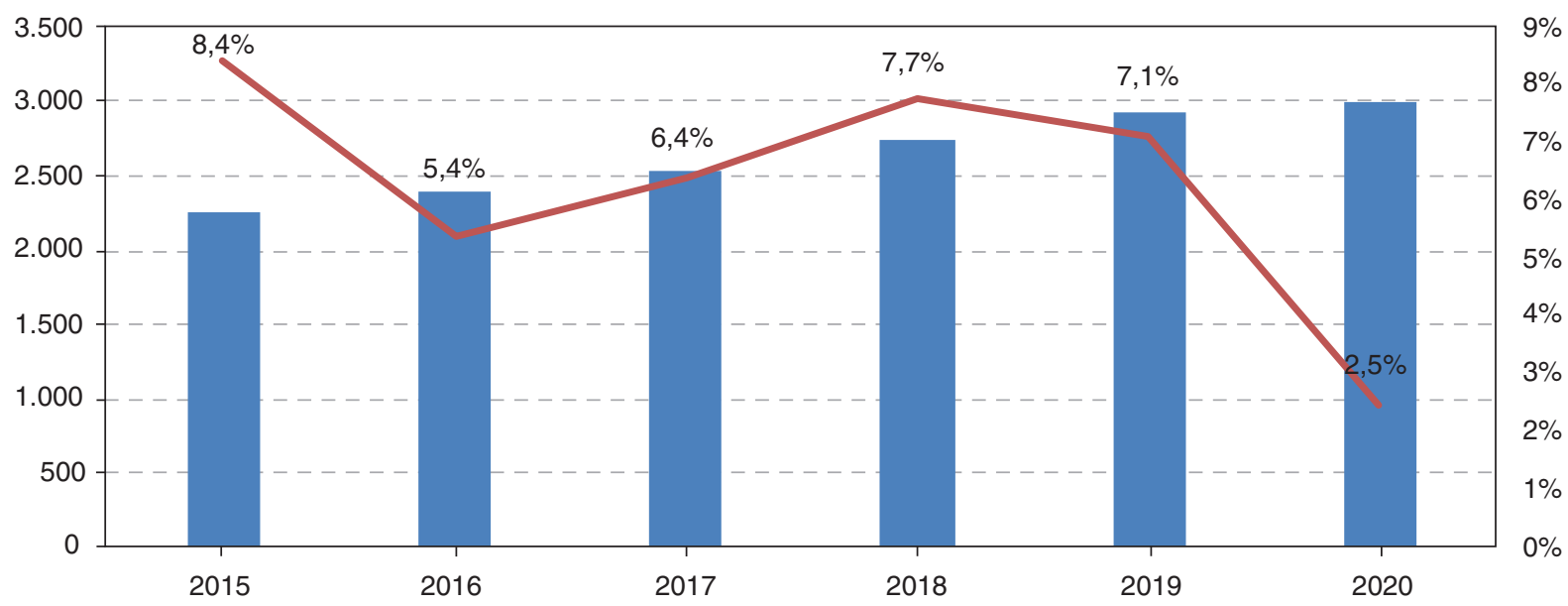

$\mathrm{N} . \stackrel{\circ}{ }$ de exportadores regulares (eje izdo.) Crecimiento (eje dcho. en \%)

Fuente: elaboración propia con datos de Estacom e ICEX, Perfil de la Empresa Exportadora. 
2018, el volumen de exportación aumenta un $13,3 \%$ y un $29,8 \%$, respectivamente, en esos dos años. Es decir, el CETA habría sido más aprovechado por los exportadores ya existentes y habría ayudado a consolidar su presencia en el mercado canadiense.

CUADRO 4 CRECIMIENTO DE EXPORTADORES REGULARES A CANADÁ

\begin{tabular}{|c|c|c|c|c|c|}
$\mathbf{2 0 1 5}$ & $\mathbf{2 0 1 6}$ & $\mathbf{2 0 1 7}$ & $\mathbf{2 0 1 8}$ & $\mathbf{2 0 1 9}$ & $\mathbf{2 0 2 0}$ \\
\hline $2,8 \%$ & $-1,2 \%$ & $13,3 \%$ & $29,8 \%$ & $16,4 \%$ & $-8,4 \%$ \\
\hline
\end{tabular}

\begin{tabular}{|l|l|l|l|l|l|}
\hline $2,8 \%$ & $-1,2 \%$ & $13,3 \%$ & $29,8 \%$ & $16,4 \%$ & $-8,4 \%$ \\
\hline
\end{tabular}

Fuente: elaboración propia con datos de Estacom e ICEX, Perfil de la Empresa Exportadora.

\subsection{Principales partidas arancelarias exportadas}

Aquellos capítulos y partidas que destacan por una evolución positiva desde la entrada en vigor del CETA ya disfrutaban, en su mayor parte, del derecho a entrar en Canadá libres de aranceles. Asimismo, en algunos casos concretos podemos relacionar la evolución de las exportaciones directamente a causas ajenas al acuerdo. Es el caso, por ejemplo, de la evolución de la partida de aviones, relacionada con la compra de aviones de búsqueda y rescate de Canadá al Grupo Airbus y que se fabrican en España, o de las ventas de motores de automóvil, que dependen de la decisión del Grupo Ford de surtir estos motores de su planta de Almussafes, Valencia, para su planta de ensamblado en Canadá.

Los casos en los que se aprecia un impacto positivo más claramente imputable al CETA son los de legumbres y hortalizas, confección femenina, carne de bovino congelada y los barcos y embarcaciones de pesca y de recreo. Todas han experimentado una evolución muy positiva tras la desaparición de los aranceles que pesaban sobre ellos. Cabe resaltar que hay que descender hasta el puesto 10 del ranking de exportación para ver los primeros productos que podemos afirmar que se han beneficiado directamente de la eliminación de aranceles del TLC.

Para los demás productos, el efecto de llamada y las medidas de facilitación del comercio del CETA han contribuido probablemente a dinamizar más las exportaciones que el desarme arancelario.

Las exportaciones de vehículos automóviles para el transporte de mercancías también parecen haberse beneficiado del CETA tras la eliminación de aranceles. En 2017 crecen un $37,6 \%$. Este es un caso similar al de los motores, puesto que se trata principalmente de las exportaciones de furgonetas Ford Transit, que se fabrican en Valencia para todo el mercado norteamericano. EI CETA, que elimina un arancel del $6,1 \%$, beneficia sin duda esta exportación, pero es difícil saber en qué medida lo ha tomado en cuenta el fabricante.

El segundo capítulo más exportado por España a Canadá es el de los productos farmacéuticos. En este grupo destaca la partida de los medicamentos para la venta al por menor ${ }^{22}$. Como hemos visto, el CETA benefició al sector de los productos farmacéuticos con la eliminación de un arancel previo de entre el $0 \%$ y el $3 \%$ y de una mayor protección de patentes. En 2020 , las exportaciones de productos farmacéuticos crecieron un 4,9\%, y hay que mencionar, dentro de este capítulo, que la partida de medicamentos (3004) creció un $11,1 \%$.

En 2020 destacan por su evolución positiva dos partidas relacionadas, la de partes de motores de avión y la de aviones de peso superior a $2.000 \mathrm{~kg}$, que corresponden a las primeras entregas de los aviones de búsqueda y rescate de Airbus.

223004 - medicamentos preparados para usos terapéuticos o profilácticos, dosificados o acondicionados para venta al por menor. 
En el sector agroalimentario no parece haberse cumplido la previsión de un aumento en las exportaciones de alimentos procesados, que tenían un arancel elevado antes del CETA.
Más bien, el efecto positivo sobre las exportaciones de agroalimentarios se ha dado en alimentos no procesados, como los agrios frescos, el aceite de oliva y la carne de bovino $\square$

CUADRO 5

RANKING DE CAPÍTULOS Y PARTIDAS TARIC POR PESO EN LAS EXPORTACIONES ESPAÑOLAS A CANADÁ EN 2020 (10 PRIMEROS Y OTRAS PARTIDAS SELECCIONADAS)

(Millones de euros)

\begin{tabular}{|c|c|c|c|c|c|c|c|c|c|}
\hline TARIC & Ranking & 2020 & 2019 & $\begin{array}{l}\text { Incremento } \\
2020\end{array}$ & $\begin{array}{l}\text { Incremento } \\
2019\end{array}$ & $\begin{array}{l}\text { Incremento } \\
2018\end{array}$ & $\begin{array}{l}\text { Incremento } \\
2017\end{array}$ & \multicolumn{2}{|c|}{$\begin{array}{l}\text { Arancel pre/post } \\
\text { CETA }\end{array}$} \\
\hline 84 Máquinas y aparatos mecánicos ... & 1 & 379,2 & 494,5 & $-23,3 \%$ & $66,7 \%$ & $84,1 \%$ & $84,7 \%$ & - & - \\
\hline 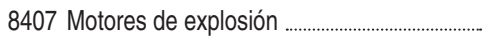 & - & 221,3 & 348,6 & $-36,5 \%$ & $107,8 \%$ & $16.797,4 \%$ & $9,8 \%$ & $0,0 \%$ & $0,0 \%$ \\
\hline $\begin{array}{l}8411 \text { Turborreactores, turbopropulsores y } \\
\text { demás turbinas de gas }\end{array}$ & - & 41,6 & 23,6 & $76,5 \%$ & $-8,6 \%$ & $2,0 \%$ & $89,2 \%$ & $0,0 \%$ & $0,0 \%$ \\
\hline Productos farmacéuticos & 2 & 243,6 & 232,3 & $4,9 \%$ & $9,3 \%$ & $-8,4 \%$ & $-16,9 \%$ & - & - \\
\hline 3004 Medicamentos & - & 229,3 & 206,4 & $11,1 \%$ & $15,9 \%$ & $-13,3 \%$ & $-6,0 \%$ & $0,0 \%$ & $0,0 \%$ \\
\hline Aeronaves; vehículos espaciales & 3 & 121,6 & 26,9 & $352,5 \%$ & $442,9 \%$ & $-52,3 \%$ & $-47,3 \%$ & - & - \\
\hline 8802 Las demás aeronaves ......... & - & 101,7 & 3,7 & $2.669,4 \%$ & $180,6 \%$ & $2.495,3 \%$ & $-32,0 \%$ & $0 \%-3 \%$ & $0,0 \%$ \\
\hline Bebidas de todo tipo (exc. zumos) ... & 4 & 121,5 & 114,2 & $6,4 \%$ & $3,5 \%$ & $4,0 \%$ & $17,9 \%$ & - & - \\
\hline 2204 Vino de uvas frescas ....................... & - & 110,9 & 106,5 & $4,2 \%$ & $4,0 \%$ & $3,8 \%$ & $17,4 \%$ & $0-4,68 \mathrm{c} / \mathrm{L}$ & $0 \mathrm{c} / \mathrm{L}$ \\
\hline Vehículos automóviles; tractores .... & 5 & 79,4 & 88,3 & $-10,1 \%$ & $-21,4 \%$ & $-13,5 \%$ & $23,3 \%$ & - & - \\
\hline $\begin{array}{l}8704 \text { Vehículos automóviles para el transporte } \\
\text { de mercancías }\end{array}$ & - & 54,7 & 51,5 & $6,2 \%$ & $4,8 \%$ & $-7,7 \%$ & $37,6 \%$ & $0 \%-6,1 \%$ & $0,0 \%$ \\
\hline Combustibles, aceites minerales .......................... & 6 & 75,8 & 113,5 & $-33,2 \%$ & $-2,7 \%$ & $4,8 \%$ & $-12,6 \%$ & - & - \\
\hline $\begin{array}{l}2710 \text { Aceites de petróleo o de minerales } \\
\text { bituminosos }\end{array}$ & - & 56,4 & 93,3 & $-39,6 \%$ & $-6,8 \%$ & $11,6 \%$ & $-21,1 \%$ & $0 \%-5 \%$ & $0,0 \%$ \\
\hline Frutas /frutos, sin conservar & 7 & 66,4 & 81,7 & $-18,7 \%$ & $1,4 \%$ & $36,8 \%$ & $28,4 \%$ & - & - \\
\hline 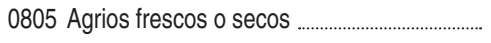 & - & 48,5 & 61,3 & $-20,9 \%$ & $-5,4 \%$ & $65,5 \%$ & $30,2 \%$ & $0,0 \%$ & $0,0 \%$ \\
\hline Grasas, aceite animal o vegetal & 8 & 45,5 & 33,5 & $36,0 \%$ & $7,6 \%$ & $29,7 \%$ & $164,2 \%$ & - & - \\
\hline 1509 Aceite de oliva & - & 38,8 & 29,9 & $29,6 \%$ & $10,1 \%$ & $24,0 \%$ & $214,6 \%$ & $0,0 \%$ & $0,0 \%$ \\
\hline 1516 Grasas y aceites, animales o vegetales ..... & - & 1,2 & 0,3 & $509,6 \%$ & $171,2 \%$ & $2.898,4 \%$ & $-79,3 \%$ & $0,0 \%$ & $0,0 \%$ \\
\hline Conservas de verdura o fruta; zumo & 9 & 44,7 & 44,5 & $0,5 \%$ & $25,9 \%$ & $-12,7 \%$ & $21,0 \%$ & - & - \\
\hline 2005 Las demás legumbres y hortalizas ......................... & - & 28,9 & 29,3 & $-1,3 \%$ & $13,8 \%$ & $-4,2 \%$ & $8,8 \%$ & $0 \%-14,5 \%$ & $0,0 \%$ \\
\hline Prendas de vestir, no de punto & 10 & 44,5 & 63,7 & $-30,2 \%$ & $-1,4 \%$ & $11,2 \%$ & $36,8 \%$ & - & - \\
\hline $\begin{array}{l}6204 \text { Trajes-sastre, conjuntos [...], para } \\
\text { mujeres o niñas }\end{array}$ & - & 20,7 & 25,9 & $-20,0 \%$ & $5,0 \%$ & $18,1 \%$ & $44,5 \%$ & $16 \%-18 \%$ & $0 \%$ \\
\hline Carne y despojos comestibles & 18 & 29,0 & 12,9 & $124,6 \%$ & $-0,5 \%$ & $10,8 \%$ & $-39,1 \%$ & - & - \\
\hline $\begin{array}{l}0202 \text { Carne de animales de la especie bovina, } \\
\text { congelada }\end{array}$ & - & 15,4 & 2,5 & $513,7 \%$ & $727,5 \%$ & - & - & $26,5 \%(1)$ & $0,0 \%(1)$ \\
\hline Barcos y embarcaciones & 22 & 21,8 & 1,3 & $1.553,8 \%$ & $-29,7 \%$ & $143,6 \%$ & $-99,2 \%$ & - & - \\
\hline 8902 Barcos de pesca; barcos de factoría .............. & - & 18,8 & 0,0 & - & $-100,0 \%$ & $1.078,1 \%$ & $-100,0 \%$ & $0 \%-25 \%$ & $0,0 \%$ \\
\hline $\begin{array}{l}8903 \text { Yates y demás barcos y embarcaciones } \\
\text { de recreo o de deporte }\end{array}$ & - & 1,6 & 1,3 & $31,2 \%$ & $-30,3 \%$ & $450,9 \%$ & $-40,5 \%$ & $0 \%-9,5 \%$ & $0,0 \%$ \\
\hline Sal, yeso, piedras sin trabajar .... & 30 & 12,8 & 8,1 & $59,4 \%$ & $37,2 \%$ & $49,3 \%$ & $-10,5 \%$ & - & - \\
\hline $\begin{array}{l}2506 \text { Cuarzo en bloques o en placas } \\
\text { cuadradas o rectangulares }\end{array}$ & - & 2,0 & 1,5 & $33,0 \%$ & $111,4 \%$ & $77.815,8 \%$ & $-99,8 \%$ & $0,0 \%$ & $0,0 \%$ \\
\hline
\end{tabular}

(1) Fuera de contingente arancelario.

Fuente: elaboración propia con datos de Estacom y Arancel de Canadá (Canadian Customs Tariff). 
congelada. Salvo la carne, ninguna de estas exportaciones estaba gravada con un arancel antes de la entrada en vigor del CETA, pero no cabe duda de que ha contribuido al crecimiento de estas exportaciones por otros motivos. El vino, que tenía un arancel positivo antes del CETA, eliminado tras la entrada en vigor provisional del acuerdo, tuvo un muy buen año en 2017, con un crecimiento del $17,4 \%$. En años posteriores, el crecimiento anual ha rondado números más modestos, con una media del $4 \%$ anual entre 2018 y 2020 . Este sector destaca, como hemos visto, por el control de los Gobiernos provinciales sobre la importación y distribución de bebidas alcohólicas en sus territorios.

La ampliación del contingente de quesos bajo el CETA no ha sido un revulsivo para las exportaciones españolas. Se esperaba que las disposiciones del acuerdo impulsaran la entrada de nuevos distribuidores en el mercado y que esto favoreciera, sobre todo, a países como España, que no tienen una tradición histórica de consumo en Canadá; a diferencia de países como Francia o Italia, cuyos productos, junto con los de Reino Unido, tienen una cuota de mercado preponderante en el segmento de quesos finos. No ha sido así, principalmente por la forma en que se administra la concesión de cuotas de importación. La UE ha hecho presión sobre Canadá para lograr una revisión de su política de adjudicación de cuotas que el país está llevando a cabo.

\section{Conclusiones}

La entrada en vigor del CETA supuso un hito en las relaciones comerciales entre la UE y Canadá. Se esperaba un efecto positivo sobre el volumen de comercio bilateral entre ambas economías, y en el caso de España parece tener margen para mejorar, a pesar del alto grado de aprovechamiento de las preferencias arancelarias que están haciendo nuestras empresas, y de la consolidación de la presencia en el mercado canadiense de exportadores regulares. El comercio de varias de las principales partidas de exportación española, medicinas o motores y vehículos comerciales, está en manos de un número reducido de empresas y corresponden a un comercio de tipo intraempresarial o están sujetas a decisiones de fabricación de multinacionales globales, y son, por lo tanto, probablemente menos permeables a la influencia de un TLC. Otros productos, como el vino o el queso, dependen de decisiones administrativas que frenan todavía el potencial que tienen. Podemos identificar, sin embargo, movimientos positivos en posiciones más bajas del ranking de exportaciones para productos que se han beneficiado de la eliminación de aranceles como la confección femenina, barcos o la carne de bovino. La eliminación de aranceles no se completará hasta 2024, por lo que todavía no podemos percibir el efecto total que tendrá. La existencia de un TLC con Canadá no parece haber animado a las empresas españolas a iniciar una actividad exportadora con este mercado, pero sí a consolidarla si existía antes. Sería interesante investigar por qué ha sido así, a pesar de las campañas informativas que se han hecho para difundir los beneficios del CETA.

\section{Bibliografía}

Comisión Europea. (2014). CETA - Summary of the final negotiating results. https://trade.ec.europa. eu/doclib/docs/2014/december/tradoc_152982. pdf 
Javier Gorriz Waddington

Comisión Europea. (2016a). The benefits of CETA. The Comprehensive Economic and Trade Agreement (CETA) between EU and Canada. https:// trade.ec.europa.eu/doclib/docs/2016/july/tradoc_154775.pdf

Comisión Europea. (2016b). CETA - An EU free trade deal fit for the $21^{\text {st }}$ century. http://trade.ec.europa. eu/doclib/press/index.cfm?id=1525

Comisión Europea. (2017a). The Economic Impact of the Comprehensive Economic and Trade Agreement (CETA). An analysis prepared by the European Commission's Directorate-General for Trade.https://trade.ec.europa.eu/doclib/docs/2017/ september/tradoc_156043.pdf

Comisión Europea. (2017b). Guide to the Comprehensive Economic and Trade Agreement (CETA). https://trade.ec.europa.eu/doclib/docs/2017/september/tradoc_156062.pdf
Comisión Europea y Global Affairs Canada. (2021). An overview of EU-Canada trade performance under CETA. Second EU-Canada CETA Joint Committee Meeting. https://trade.ec.europa.eu/ doclib/docs/2021/april/tradoc_159548.pdf

Serrano, C. (2021). El Comprehensive Economic and Trade Agreement (CETA) con Canadá. Implicaciones para España (Documento de Trabajo, Serie Unión Europea y Relaciones Internacionales, n.. 109/2021). CEU Real Instituto Universitario de Estudios Europeos. Universidad San Pablo. https://repositorioinstitucional.ceu.es/ bitstream/10637/12547/1/comprenhensive serrano_2021.pdf

Unión Europea. (2020). How EU Businesses Can Take Advantage Of Public Procurement Opportunities In Canada Under CETA, A Practical Business Guide. https://trade.ec.europa.eu/doclib/ docs/2020/february/tradoc_158655.pdf 